\title{
Effect of phenylephrine infusion on atrial electrophysiological properties
}

\author{
James W Leitch, Magdy Basta, Peter J Fletcher
}

\begin{abstract}
Objective-To determine the effect of changes in autonomic tone induced by phenylephrine infusion on atrial refractoriness and conduction.

Design-Left and right atrial electrophysiological properties were measured before and after a constant phenylephrine infusion designed to increase sinus cycle length by $25 \%$.

Subjects-20 patients, aged 53 (SD 6)
\end{abstract} years, undergoing electrophysiological study for investigation of idiopathic paroxysmal atrial fibrillation (seven patients) or for routine follow up after successful catheter ablation of supraventricular tachycardia (13 patients).

Main outcome measures-Changes in left and right atrial effective refractory periods, atrial activation times, and frequency of induction of atrial fibrillation. Results-Phenylephrine (mean dose 69 (SD 18) $\mathrm{mg} / \mathrm{min}$ ) increased mean blood pressure by 22 (12) $\mathrm{mm} \mathrm{Hg}$ (range 7 to 44) and lengthened sinus cycle length by 223 (94) $\mathrm{ms}(20$ to 430$)$. Left atrial effective refractory period lengthened following phenylephrine infusion from 250 (25) to 264 (21) $\mathrm{ms}(P<0.001)$ but there was no significant change in right atrial effective refractory period: $200(20) v 206(29), P=$ $0 \cdot 11$. There was a significant relation between the effect of phenylephrine on sinus cycle length and on right atrial refractoriness $(r=0.6, P=0.005)$ with shortening of right atrial refractoriness in patients with the greatest prolongation in sinus cycle length. During phenylephrine infusion, the right atrial stimulus to left atrial activation time at the basic pacing cycle length of $600 \mathrm{~ms}$ was unchanged, at 130 (18) $v 131$ (17) ms, but activation delay with a premature extrastimulus increased: 212 (28) $v 227$ (38) $\mathrm{ms}, P=$ $0 \cdot 002$. Atrial fibrillation was induced by two of 58 refractory period measurements at baseline and by 12 of 61 measurements during phenylephrine infusion $(P<0.01)$. Phenylephrine increased the difference between left and right atrial refractory periods by $22.8(19.4) \mathrm{ms}$ in the five patients with induced atrial fibrillation after phenylephrine compared to 0.9 $(16 \cdot 2) \mathrm{ms}$ in the 13 patients without induced atrial fibrillation after phenylephrine infusion $(P=0.02)$.

Conclusions-Phenylephrine infusion increased left atrial refractoriness and intra-atrial conduction delay following a premature right atrial extrastimulus. Induction of atrial fibrillation during phenylephrine infusion was associated with non-uniform changes in atrial refractoriness. These data support the concept that changes in autonomic tone may precipitate atrial fibrillation in susceptible individuals.

(Heart 1997;78:166-170)

Keywords: phenylephrine; atria; electrophysiological properties; refractoriness; intra-atrial conduction delay

In animal models, direct vagal stimulation shortens atrial refractoriness in a non-uniform manner facilitating the induction of atrial fibrillation. ${ }^{1-3}$ Changes in autonomic tone have been linked to the onset of atrial fibrillation in some individuals ${ }^{4-6}$ but whether this is a frequent occurrence is uncertain. Vagal stimulation shortens right atrial refractoriness acutely in humans. ${ }^{7}$ However, the effect of a more sustained increase in vagal tone has not been evaluated. The aim of this study was to determine the effect of a sustained increase in vagal tone induced indirectly by phenylephrine infusion on atrial electrophysiological properties.

\section{Methods}

SUBJECTS

Twenty patients who were undergoing electrophysiological study for investigation of idiopathic paroxysmal atrial fibrillation (seven patients) or as routine follow up after successful catheter ablation of supraventricular tachycardia (13 patients) underwent a research study. In the latter patients, catheter ablation had been performed at least three months previously with a median of two radiofrequency applications (mean (SD) $3.5(4 \cdot 8)$ ). The procedure was slow pathway ablation (10 patients), ablation of a left posterolateral accessory pathway (two patients) and ablation of a left posteroseptal accessory pathway (one patient). No patient had inducible atrioventricular node reentry tachycardia or evidence of accessory pathway conduction at this study. Clinical details are shown in table 1.

\section{ELECTROPHYSIOLOGICAL STUDY}

An electrophysiological study was performed after mild sedation with meperidine (50 to $100 \mathrm{mg}$ ) and midazolam ( 2 to $4 \mathrm{mg}$ ), repeated as necessary. A quadripolar catheter with 
Table 1 Baseline data and changes after phenylephrine infusion

\begin{tabular}{|c|c|c|c|c|c|c|c|c|c|c|c|c|c|}
\hline \multirow[b]{2}{*}{ Patient } & \multirow[b]{2}{*}{$\mathrm{Age}$} & \multirow[b]{2}{*}{ Diagnosis } & \multirow[b]{2}{*}{ Sex } & \multirow{2}{*}{$\begin{array}{l}\text { Phenyle- } \\
\text { phrine } \\
\text { dose } \\
\text { ( } \mu \text { g/min) }\end{array}$} & \multicolumn{2}{|l|}{$S C L$} & \multicolumn{2}{|l|}{$R A E R P$} & \multicolumn{2}{|l|}{$L A E R P$} & \multicolumn{2}{|c|}{$\begin{array}{l}\text { Activation time } \\
H R A S 2 \text { to } C S(5,6)\end{array}$} & \multirow{2}{*}{$\begin{array}{l}\text { AF } \\
\text { after } \\
\text { phenyle- } \\
\text { phrine }\end{array}$} \\
\hline & & & & & $\begin{array}{l}\text { Control } \\
\text { (ms) }\end{array}$ & $\begin{array}{l}\Delta \\
\%\end{array}$ & $\begin{array}{l}\text { Control } \\
(m s)\end{array}$ & $\underset{(m s)}{\Delta}$ & $\begin{array}{l}\text { Control } \\
\text { (ms) }\end{array}$ & $\underset{(m s)}{\Delta}$ & $\begin{array}{l}\text { Control } \\
\text { (ms) }\end{array}$ & $\underset{(m s)}{\Delta}$ & \\
\hline $\begin{array}{l}1 \\
2 \\
3 \\
4 \\
5 \\
6 \\
7 \\
8 \\
9 \\
10 \\
11 \\
12 \\
13 \\
14 \\
15 \\
16 \\
17 \\
18 \\
19 \\
20 \\
\text { Mean } \\
\text { SD }\end{array}$ & $\begin{array}{l}46 \\
52 \\
58 \\
45 \\
58 \\
59 \\
51 \\
39 \\
52 \\
60 \\
59 \\
54 \\
30 \\
28 \\
29 \\
51 \\
42 \\
24 \\
58 \\
51 \\
47 \\
11 \cdot 6\end{array}$ & $\begin{array}{l}\text { AF } \\
\text { AF } \\
\text { AF } \\
\text { AF } \\
\text { AF } \\
\text { AF } \\
\text { AF } \\
\text { SVT } \\
\text { SVT } \\
\text { SVT } \\
\text { SVT } \\
\text { SVT } \\
\text { SVT } \\
\text { SVT } \\
\text { SVT } \\
\text { SVT } \\
\text { SVT } \\
\text { SVT } \\
\text { SVT } \\
\text { SVT }\end{array}$ & $\begin{array}{l}\mathbf{M} \\
\mathbf{M} \\
\mathbf{M} \\
\mathbf{F} \\
\mathbf{M} \\
\mathbf{M} \\
\mathbf{M} \\
\mathbf{F} \\
\mathbf{F} \\
\mathbf{F} \\
\mathbf{F} \\
\mathbf{F} \\
\mathbf{F} \\
\mathbf{F} \\
\mathbf{F} \\
\mathbf{F} \\
\mathbf{M} \\
\mathbf{F} \\
\mathbf{F} \\
\mathbf{F}\end{array}$ & $\begin{array}{r}80 \\
80 \\
80 \\
60 \\
100 \\
80 \\
80 \\
60 \\
60 \\
40 \\
60 \\
60 \\
60 \\
60 \\
100 \\
40 \\
60 \\
60 \\
100 \\
60 \\
69 \cdot 0 \\
17 \cdot 7\end{array}$ & $\begin{array}{r}980 \\
810 \\
830 \\
670 \\
820 \\
930 \\
920 \\
630 \\
800 \\
980 \\
750 \\
810 \\
580 \\
590 \\
590 \\
710 \\
655 \\
830 \\
740 \\
780 \\
770 \cdot 3 \\
125 \cdot 4\end{array}$ & $\begin{array}{c}44 \\
25 \\
30 \\
18 \\
18 \\
35 \\
25 \\
60 \\
39 \\
23 \\
23 \\
25 \\
45 \\
32 \\
22 \\
36 \\
25 \\
33 \\
3 \\
22 \\
29 \cdot 2 \\
12 \cdot 2\end{array}$ & $\begin{array}{l}220 \\
217 \\
197 \\
178 \\
200 \\
232 \\
218 \\
168 \\
212 \\
190 \\
222 \\
198 \\
163 \\
183 \\
221 \\
207 \\
183 \\
213 \\
178 \\
200 \\
200 \cdot 0 \\
19 \cdot 7\end{array}$ & $\begin{array}{r}-23 \\
3 \\
6 \\
15 \\
22 \\
33 \\
37 \\
-20 \\
-15 \\
-13 \\
-7 \\
-5 \\
-2 \\
5 \\
6 \\
8 \\
10 \\
15 \\
24 \\
32 \\
6 \cdot 6 \\
17 \cdot 5\end{array}$ & $\begin{array}{c}277 \\
293 \\
245 \\
223 \\
270 \\
280 \\
270 \\
215 \\
262 \\
248 \\
258 \\
251 \\
\\
210 \\
290 \\
237 \\
227 \\
233 \\
237 \\
227 \\
250 \cdot 2 \\
25 \cdot 1\end{array}$ & $\begin{array}{r}11 \\
3 \\
20 \\
20 \\
26 \\
16 \\
1 \\
25 \\
-1 \\
17 \\
15 \\
4 \\
23 \\
-7 \\
3 \\
16 \\
22 \\
20 \\
25 \\
13.6 \\
10.1\end{array}$ & $\begin{array}{r}265 \\
210 \\
235 \\
190 \\
240 \\
250 \\
238 \\
204 \\
230 \\
230 \\
190 \\
238 \\
175 \\
210 \\
170 \\
185 \\
195 \\
162 \\
200 \\
215 \\
212 \\
28\end{array}$ & $\begin{array}{r}55 \\
13 \\
15 \\
8 \\
30 \\
17 \\
2 \\
56 \\
45 \\
10 \\
18 \\
7 \\
5 \\
0 \\
30 \\
15 \\
5 \\
11 \\
-8 \\
-15 \\
16 \\
19\end{array}$ & $\begin{array}{l}\text { Yes } \\
\text { Yes } \\
\text { No } \\
\text { Yes } \\
\text { No } \\
\text { No } \\
\text { No } \\
\text { Yes } \\
\text { No } \\
\text { Yes } \\
\text { No } \\
\text { No } \\
\text { No } \\
\text { No } \\
\text { No } \\
\text { No } \\
\text { No } \\
\text { No } \\
\text { No } \\
\text { No }\end{array}$ \\
\hline
\end{tabular}

SCL, sinus cycle length; RAERP, right atrial effective refractory period; LAERP, left atrial effective refractory period; S2, premature extrastimulus; HRA, high right atrium; CD, coronary sinus; AF, atrial fibrillation; SVT, previous catheter ablation for supraventricular tachycardia.

$1 \mathrm{~mm}$ electrode spacing was positioned in the right atrial appendage. Catheter position was confirmed by biplane fluoroscopy. A catheter with four pairs of electrodes $(1 \mathrm{~mm}$ separation between the electrodes in each pair and 10 $\mathrm{mm}$ between each pair of electrodes) was positioned in the coronary sinus and advanced until the proximal electrode pair was $1 \mathrm{~cm}$ inside the coronary sinus. Stimulation was performed with a Medtronic 5328 stimulator (Medtronic Inc, Minneapolis, USA) at four times diastolic threshold from the distal two electrodes in the right atrial catheter and from the second most proximal pair of electrodes in the coronary sinus. Bipolar recordings were made from the proximal right atrial electrodes, from the three remaining coronary sinus electrode pairs, and from a catheter positioned at the His bundle recording position. Signals were filtered at 0.5 to $500 \mathrm{~Hz}$ and recorded on a Siemens Mingograph 7 (Siemens-Elema AB, Solna Sweden) at paper speed $100 \mathrm{~mm} / \mathrm{s}$.

ATRIAL REFRACTORY PERIODS

Atrial refractory periods were determined with an extrastimulus introduced after an eight beat train of stimuli with a one second pause between each train of stimuli. The drive cycle length was $600 \mathrm{~ms}$ in 16 patients and $500 \mathrm{~ms}$ in four. After initial approximate determination of the atrial effective refractory period, the extrastimulus was introduced $30 \mathrm{~ms}$ less than the refractory period and incremented in $5 \mathrm{~ms}$ steps until atrial capture was achieved. The longest S1-S2 which failed to capture the atrium was defined as the effective refractory period. This sequence was repeated three times and the mean effective refractory period recorded. The number of repetitive atrial responses induced by the atrial extrastimulus which captured the atrium during each sequence was recorded. Sustained atrial fibrillation was defined as more than 30 repetitive atrial responses.
ATRIAL ACTIVATION TIME

Atrial activation time was measured during right atrial pacing from the stimulus artefact to the atrial depolarisations in the coronary sinus and during left atrial pacing, from the stimulus artefact to the right atrial depolarisation. Activation time was measured at the basic pacing cycle length and with delivery of the premature extrastimulus at the functional refractory period of the atrium.

\section{PHENYLEPHRINE INFUSION}

After measurement of baseline electrophysiological variables, phenylephrine was infused into a peripheral vein at a rate of $20 \mathrm{mg} / \mathrm{min}^{8}$ and increased by $20 \mathrm{mg} / \mathrm{min}$ every five minutes until a $25 \%$ increase in sinus cycle length had been achieved (19 patients) or until mean blood pressure increased by $40 \mathrm{~mm} \mathrm{Hg}$ (one patient). In some cases, the final dose resulted in $>25 \%$ increase in sinus cycle length; if this occurred the infusion rate was not reduced. The infusion was continued for 10 minutes at the final dose to achieve a steady state before repeat electrophysiological measurements were made. The order of measurement of right and left atrial refractory periods after phenylephrine infusion was randomised. At each dose level, sinus cycle length was measured over a 10 second interval.

\section{STATISTICS}

Changes in electrophysiological variables were compared with paired and unpaired $t$ tests as appropriate. The relation between changes in the electrophysiological variables and in sinus cycle length was evaluated by simple linear regression. The frequency of induction of atrial fibrillation before and after phenylephrine infusion was compared using a logistic regression model which allowed for individual patient response rates. The number of patients with induced atrial fibrillation before and after phenylephrine infusion was compared with an 
Figure 1 Significant relation between the change in sinus cycle length and the change in right atrial effective refractory period $(r=0 \cdot 6, P=0.005)$. SCL, sinus cycle length; $R A E R P$, right atrial effective refractory period.

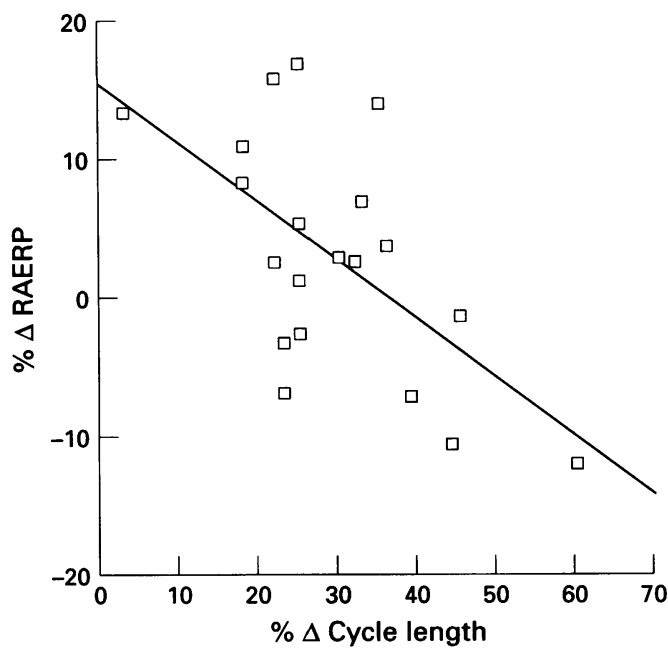

Table 2 Atrial activation times at baseline and after phenylephrine infusion

\begin{tabular}{lcc}
\hline & Baseline & Phenylephrine \\
\hline Right atrial pacing: & & \\
S1 to CS $(5,6)$ & $130(18)$ & $131(17)$ \\
S2 to HRA & $43(9)$ & $40(10)$ \\
S2 to CS $(1,2)$ & $183(34)$ & $191(33)^{\star}$ \\
S2 to CS $(5,6)$ & $212(28)$ & $228(38) \dagger$ \\
S2 to CS $(7,8)$ & $218(31)$ & $234(39) \dagger$ \\
Left atrial pacing CS $(3,4):$ & $112(20)$ & $112(20)$ \\
S1 to HRA & $150(23)$ & $154(24)$ \\
S2 to HRA & \\
\hline
\end{tabular}

S1, Stimulus artefact at the basic pacing cycle length S2, stimulus artefact with the premature extrastimulus; CS coronary sinus (electrode numbers in brackets with 1 being the most proximal electrode and 8 the most distal electrode); HRA, high right atrium.

$\star P<0.05 ;+P<0.001$

exact McNemar's test. Continuous data are reported as mean (SD).

\section{Results}

At baseline mean blood pressure was 95 (13) $\mathrm{mm} \mathrm{Hg}$ and sinus cycle length was 770 (125) ms. Phenylephrine infusion (mean dose 69 (18) $\mathrm{mg} / \mathrm{min}$ ) increased blood pressure by 22 (12) $\mathrm{mm} \mathrm{Hg}$ (range 7 to 44 ) and lengthened sinus cycle length by 223 (94) $\mathrm{ms}$ ( 20 to 430 ). The mean change in sinus cycle length was $29(12) \%$.

Changes in atrial refractory periods are shown in table 1 . Left atrial effective refractory
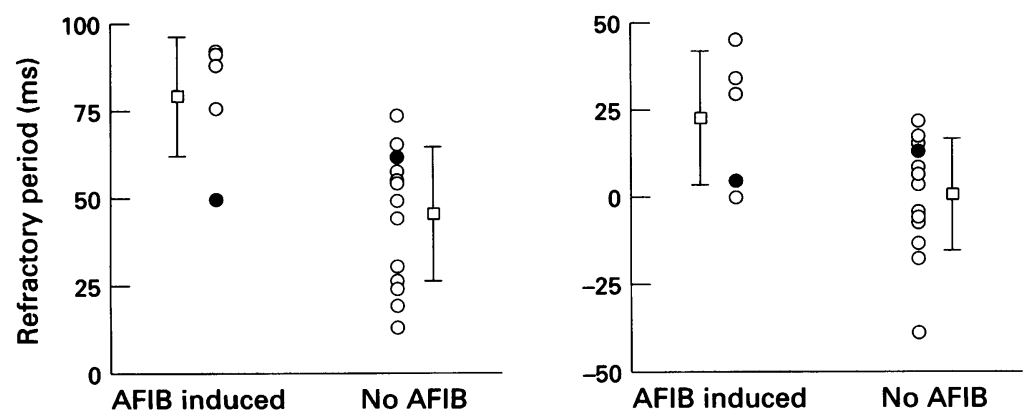
Figure 2 Difference between right and left atrial refractory periods after phenylephrine
infusion (left graph) and the change in this measurement after phenylephrine infusion (right graph). The filled circles indicate the two patients with inducible atrial fibrillation at baseline. Patients in whom atrial fibrillation was induced after phenylephrine had a greater difference between left and right atrial refractory periods $(P=0.01)$ and had a greater increase in this variable after phenylephrine $(P=0.02)$ than the patients in whom atrial fibrillation was not induced. period lengthened consistently following phenylephrine infusion, from 250 (25) to 264 (21) $\mathrm{ms}(\mathrm{P}<0.001)$. In contrast, there was no significant change in right atrial effective refractory period $(200(20) v 206$ (29), $\mathrm{P}=$ $0 \cdot 11$ ), with shortening in seven patients and lengthening in 13. There was a significant relation between the change in sinus cycle length and the change in right atrial refractory period induced by phenylephrine $(r=0.6 ; \mathrm{P}=$ 0.005 ) (fig 1). The change in left atrial refractoriness was not related to the change in sinus cycle length $(r=0 \cdot 1 ; \mathrm{P}=0.9)$. Patients who had previously undergone catheter ablation had similar changes in atrial effective refractory periods to the patients with a history of atrial fibrillation who had not undergone catheter ablation (table 1).

Changes in left and right atrial activation times are shown in table 2. During right atrial pacing at the basic cycle length of $600 \mathrm{~ms}$, left atrial activation time was unchanged after phenylephrine, at 130 (18) $v 131$ (17) ms. Left atrial activation delay, with the right atrial extrastimulus increased after phenylephrine (table 2, $\mathrm{P}<0.05$ for all coronary sinus recording electrodes). For example, activation delay to the atrial recording at the fifth and sixth coronary sinus electrodes increased from 212 (28) to 228 (38) $\mathrm{ms}, P=0.001$. Activation delay to the right atrium following the left atrial extrastimulus did not increase after phenylephrine: 150 (23) $v 154$ (24) ms.

Sustained atrial fibrillation ( $>30$ cycles) was induced in two patients at baseline and in five patients after phenylephrine $(P=N S)$. The frequency of induction of atrial fibrillation episodes was increased after phenylephrine infusion. At baseline, atrial fibrillation was induced by two of 58 determinations of right atrial effective refractory period, and after phenylephrine infusion by 12 of 61 right atrial refractory period determinations $(P<0.01)$. In no instance, either at baseline or during phenylephrine infusion, was atrial fibrillation induced by left atrial stimulation. Phenylephrine increased the difference between left and right atrial refractory periods by $22 \cdot 8$ $(19.4) \mathrm{ms}$ in the five patients with inducible atrial fibrillation after phenylephrine infusion, compared with $0.9(16.2) \mathrm{ms}$ in the patients without inducible atrial fibrillation $(P=0.02)$ (fig 2).

\section{Discussion}

The effect of phenylephrine infusion on atrial electrophysiological properties in humans has not been studied before. Phenylephrine was given in order to induce a sustained increase in vagal tone with the expectation that atrial refractory periods would shorten in a non-uniform manner and that atrial fibrillation would be induced more frequently..$^{1-3}$ 10-12 $^{-12}$ Contrary to our expectations, the main effect of phenylephrine infusion was to lengthen atrial refractoriness in the left atrium. However, the non-uniform changes in refractoriness were associated with an increased frequency of induction of atrial fibrillation. 


\section{ATRIAL REFRACTORY PERIODS}

In animals, direct vagal stimulation shortens refractoriness more in the right than in the left atrium, probably because of the non-uniform distribution of vagal nerve endings. ${ }^{1-3}$ In one study, ${ }^{3}$ vagal stimulation shortened refractory periods in the right atrial appendage by between $59 \%$ and $45 \%$ compared to between $16 \%$ and $26 \%$ in the low posterior left atrium. The change in refractory period in the right atrial appendage was greater than in any of the four left atrial sites sampled. ${ }^{3}$

Stimulation of the ansae subclaviae also shortens right atrial refractoriness. ${ }^{3}$ Since a constant infusion of phenylephrine results in a decrease in sympathetic outflow ${ }^{12}$ as well as an increase in vagal stimulation, the net effect of phenylephrine infusion on atrial refractory period will vary depending upon the relative influence of vagal and adrenergic stimulation. ${ }^{13}$ Lengthening of atrial refractory periods during phenylephrine infusion, particularly in the left atrium where there is relatively sparse vagal innervation, may be explained by the predominant effects of adrenergic withdrawal.

The results of the animal studies may not be directly comparable to the results of this study. The rise in blood pressure, and the consequent decrease in sinus cycle length induced by phenylephrine, were relatively modest when compared to the animal experiments in which two- to threefold increases in sinus cycle length were obtained by direct vagal stimulation. ${ }^{2}$ As suggested by fig 1 , a stronger stimulus (a higher dose of phenylephrine with a target of $30-35 \%$ increase in sinus cycle length) may have produced a more consistent shortening of right atrial refractoriness.

An important limitation of this study was the use of phenylephrine to induce reflex changes in autonomic tone. Some of the electrophysiological effects may have resulted from direct $\alpha$ stimulation. ${ }^{14}{ }^{15}$ In general, however, the direct electrophysiological effects of phenylephrine are relatively minor when compared to the indirect reflex changes. ${ }^{1617}$ Specifically, phenylephrine has no discernible effect on atrial refractoriness in dogs pretreated with nadalol and atropine. ${ }^{18}$

A potential limitation may be the effect of previous catheter ablation on the response to phenylephrine. Slow pathway ablation in particular may have significant effects on cardiac autonomic function. ${ }^{19}$ These effects, however, resolve within one month of ablation ${ }^{19}$ and in this study no major differences were observed in the response of the two groups of patients to phenylephrine infusion.

\section{ATRIAL ARRHYTHMIAS}

Although atrial refractory periods did not shorten significantly with phenylephrine infusion, atrial fibrillation was induced more often. This effect was mainly confined to a small number of patients with marked changes in atrial refractoriness (fig 2). The non-uniform changes in refractoriness in the left and right atria in these patients may have enhanced the induction of atrial fibrillation by increasing the dispersion of repolarisation. ${ }^{1-39-112021}$ Another potentially important factor was the increase in intra-atrial conduction delay with a premature atrial extrastimulus. ${ }^{22}$ The delay in the propagation of a premature impulse to the left atrium may be a manifestation of the increase in left atrial refractory period and increased dispersion of repolarisation. ${ }^{23}$ Local block of a premature impulse occurs in areas with delayed restoration of excitability. ${ }^{23}$ An increase in intra-atrial conduction delay with premature stimuli is a characteristic finding in patients with idiopathic atrial fibrillation. ${ }^{24-26}$

In summary, phenylephrine infusion was associated with non-uniform changes in left and right atrial refractoriness and increased intra-atrial conduction delay following a premature right atrial extrastimulus. Induction of atrial fibrillation was associated with non-uniform changes in atrial refractoriness. These data support the concept that changes in autonomic tone may precipitate atrial fibrillation in susceptible individuals.

1 Alessi R, Nusynowitz M, Abildskov JA, Moe GK Nonuniform distribution of vagal effects on the atrial refractory period. Am $\mathcal{J}$ Physiol 1958;194:406-10.

2 Ninomiya I. Direct evidence of nonuniform distribution of vagal effects on dog atria. Circ Res 1966;19:576-83.

3 Zipes DP, Mihalick MJ, Robbins GT. Effects of selective vagal and stellate ganglion stimulation on atrial refractoriness. Cardiovasc Res 1974;8:647-55

4 Coumel P, Leclercq JF, Attuel P, Lavallee JP, Flammang $D$. Autonomic influences in the genesis of atrial arrhythmias: atrial flutter and fibrillation of vagal origin. In: Narula OS, ed. Cardiac arrhythmias: electrophysiology, diagnosis and management. Baltimore: Williams and Wilkins, 1979:243-55

5 Coumel P, Friocourt P, Mugica J, Attuel P, Ecelercq JF. Long-term prevention of vagal atrial arrhythmias by atria pacing at $90 / \mathrm{m}$

6 Leitch J, Klein G, Yee R, Murdock C, Teo WS. Neurally mediated syncope and atrial fibrillation. $N$ Engl $f$ Med 1991;324:495-6.

7 Prystowsky EN, Naccarelli GV, Jackman WM, Rinkenberger RL, Heger JJ, Zipes DP. Enhanced parasympathetic tone shortens atrial refractoriness in man Am $\mathcal{f}$ Cardiol 1983;51:96-100.

8 Facchini M, De Ferrari GM, Bonazzi O, Weiss $T$, Schwartz PJ. Effect of reflex vagal activation on the frequency of ventricular premature complexes. $A m \mathcal{F} \mathrm{Cardiol}$ 1991;68:349-54

9 Wang Z, Page P, Nattel S. Mechanism of flecainide's antiarrhythmic action in experimental atrial fibrillation. Circ Res 1992;71:271-87.

10 Rensma PL, Allessie MA, Lammers WJFP, Bonke FIM, Schalij MJ. Length of excitation wave and susceptibility to reentrant atrial arrhythmias in normal conscious dogs. Circ Res 1988;62:395-410.

11 Schuesser RB, Grayson TM, Bromberg BI, Cox JL, Boineau JP. Cholinergically mediated tachyarrhythmias induced by a single extra-stimulus in the isolated canine induced by a single extra-stimulus in the
right atrium. Circ Res 1992;71:1254-67.

12 Saul JP, Rea RF, Eckberg DL, Berger RD, Cohen RJ. Heart rate and muscle sympathetic nerve variability during reflex changes of autonomic activity. Am F Physiol 1990 258:H713-21

13 Inoue $H, Z$ Zipes DP. Changes in atrial and ventricular refractoriness and in atrioventricular nodal conduction produced by combinations of vagal and sympathetic stimulation that result in a constant spontaneous sinus cycle length. Circ Res 1987;60:942-51.

14 Pardini BJ, Lund DD, Schmid PG. Contrasting preganglionic and postganglionic effects of phenylephrine on parasympathetic control of heart rate. Am F Physiol 1991; 260:H118-22.

15 Rosen MR, Bilexikian JP, Cohen IS, Robinson RB. Adrenergic modulation of cardiac rhythm. In: Zipes DP, Jalife J, eds. Cardiac electrophysiology From cell to bedside. Philadelphia: W B Saunders, 1991:300-4.

16 Beck W, Barnard CN, Schrire V. Heart rate after cardiac transplantation. Circulation 1969;40:437-45.

17 Warner MR, Loeb JM. Reflex regulation of atrioventricular conduction. $A m \mathcal{F}$ Physiol 1987;252:H1077-85.

18 Talajic M, Villemaire C, Nattel S. Electrophysiologic effects of alpha-adrenergic stimulation. PACE 1990;13: 578-82.

19 Kocovic DZ, Harada T, Shea JB, Soroff D, Friedman PL. Alterations of heart rate and of heart rate variability after radiofrequency ablation. Delineation of parasympathetic radiofrequency ablation. Delineation of parasympathetic
pathways in the human heart. Circulation 1993;88: pathways
$1671-81$. 
20 Misier ARR, Opthof T, Van Hemel NM, Defauw JJAM, DeBakker JMT, Janse MJ, et al. Increased dispersion of "refractoriness" in patients with idiopathic paroxysmal atrial fibrillation. $f$ Am Coll Cardiol 1992;19:1531-5.

21 Smith JM, Kaplan DT, Cohen RJ. The physics of reentry and fibrillation. In: Zipes DP, Jalife J, eds. Cardiac electrophysiology. From cell to bedside. Philadelphia: W B Saunders, 1991:215-23.

22 Allessie MA, Bonke FIM, Schopman FJG. Circus movement in rabbit atrial muscle as a mechanism of tachycardia. III. The "leading circle" concept: a new model of circus movement in cardiac tissue without the involvecircus movement in cardiac tissue without the involve-

23 Allessie MA, Bonke FIM, Schopman FJ. Circus movement in rabbit atrial muscle as a mechanism of tachycardia. II.
The role of nonuniform recovery of excitability in the occurrence of unidirectional block, as studied with multiple microelectrodes. Circ Res 1976;39:168-77.

24 Kumagai K, Akimitsu S, Kawahira K, Kawanami F, Yamanouchi Y, Hiroki $\mathrm{T}$, et al. Electrophysiological properties in chronic lone atrial fibrillation Circulation 1991;84:1662-8.

25 Buxton AE, Waxman HL, Marchlinski FE, Josephson ME. Atrial conduction: effects of extrastimuli with and without atrial dysrhythmias. Am f Cardiol 1984;54:755-61.

26 Cosio FG, Palacios J, Vidal JM, Cocina EG, GomezSanches MA, Tamargo L. Electrophysiologic studies in atrial fibrillation. Slow conduction of premature impulses: a possible manifestation of the background for reentry. Am $\mathcal{F}$ Cardiol 1983;51:122-30. 